University of Wollongong

Research Online

Faculty of Engineering - Papers (Archive)

Faculty of Engineering and Information

Sciences

February 2004

\title{
A two-stage decision support tool for restoring tidal flows to flood mitigation drains affected by acid sulfate soil: case study of Broughton Creek floodplain, New South Wales, Australia
}

W. Glamore

University of New South Wales

Buddhima Indraratna

University of Wollongong, indra@uow.edu.au

Follow this and additional works at: https://ro.uow.edu.au/engpapers

Part of the Engineering Commons

https://ro.uow.edu.au/engpapers/408

\section{Recommended Citation}

Glamore, W. and Indraratna, Buddhima: A two-stage decision support tool for restoring tidal flows to flood mitigation drains affected by acid sulfate soil: case study of Broughton Creek floodplain, New South Wales, Australia 2004.

https://ro.uow.edu.au/engpapers/408

Research Online is the open access institutional repository for the University of Wollongong. For further information contact the UOW Library: research-pubs@uow.edu.au 


\title{
A two-stage decision support tool for restoring tidal flows to flood mitigation drains affected by acid sulfate soil: case study of Broughton Creek floodplain, New South Wales, Australia
}

\author{
William Glamore ${ }^{\text {A.C }}$ and Buddhima Indraratna ${ }^{\mathrm{B}}$ \\ A Water Research Laboratory, University of New South Wales, NSW 2000, Australia. \\ ${ }^{\mathrm{B}}$ Division of Civil and Environmental Engineering, University of Wollongong, NSW 2522, Australia. \\ ${ }^{C}$ Corresponding authour; email: W.Glamore $@$,wrl.unsw.edu.au
}

\begin{abstract}
A 2-stage flood estimation and water quality decision support tool (DST) was developed, calibrated, and applied to a field site in south-eastern New South Wales (NSW) to simulate tidal restoration in a flood mitigation drain affected by acid sulfate soils leachate. The first stage of the DST employs a digital terrain map, geographic information tools, and measured water levels to calculate drain water overtopping due to tidal variations. Simulations using the GIS technique at the study site indicated that the primary drainage network can safely contain full tidal flushing ( $0.91 \mathrm{~m} \mathrm{AHD}$ or a $58 \%$ increase), whereas at the same level the secondary drainage network overtops along relict drainage channels. The second stage of the DST simulates the change in drain water quality using an ion-specific program code written within the open interface PHREEQC program. The results from the water quality model were calibrated against laboratory titration tests. Drain water $\mathrm{pH}$ was shown to increase above 6.0, and soluble aluminium and iron concentrations decreased by $73 \%$ and $56 \%$, respectively. The extent of water quality change is directly related to the ionic strength of the intruding water and the ion-specific reaction kinetics of aluminium, iron, and sulfate.

Based on the DST simulations, floodgate modifications to restore tidal flushing were successfully undertaken at a study site near Berry, in south-eastern NSW. DST predictions accurately simulated field results $( \pm 10 \%)$ and slight variations between data were attributed to the prolonged drought at the field site, which increased the ionic strength of intruding waters, and the high concentration of sulfate in seawater. The DST can be easily adapted to other sites throughout Australia.
\end{abstract}

Additional keywords: acid sulfate soils, ion association model, saline intrusion, tidal restoration, water quality, acid buffering.

\section{Introduction}

The translocation of acid sulfate soil (ASS) oxidation products into adjacent surface waters can cause broad-scale acidification of receiving waters. These impacts are often exacerbated by 1 -way floodgates which restrict tidal flushing within flood mitigation drains and limit tidal buffering. Restoration of tidal flows via modified floodgates is a wellreported means of improving geochemical, hydrodynamic, and acid transport conditions within ASS-affected drains (Glamore and Indraratna 2002; Indraratna et al. 2002; Glamore 2003; Johnston et al. 2002).

Permitting tidal flows within flood mitigation drains via modified floodgates is a complex and potentially highrisk procedure. If mismanaged, tidal flows, which often contain salinity concentrations in excess of ANZECC (2000) irrigation criteria, can overtop the drain levee bank causing inundation of low-lying floodplains with saline or brackish water. In regions where the lateral hydraulic conductivity of the soil is high ( $>15 \mathrm{~m} /$ day), saline intrusion into the soil matrix and subsequent migration of chloride salts into the root-zone may also decrease agricultural productivity. Furthermore, in some backswamp environments, tidal waters may not have sufficient neutralising agents to warrant floodgate modifications and other remediation methods may be more cost-effective.

The effectiveness of tidal restoration as an acid buffering strategy is reliant on many complex factors, including groundwater transport, acid production rates, and estuarine flushing dynamics. Importantly, acid neutralisation via carbonate/bicarbonate buffering, as well as dilution, must be considered when calculating the potential for estuarine waters to neutralise acid oxidation products (Glamore and Indraratna 2001). However, at any one point in an estuary the buffering capacity will vary according to the tidal dynamics, dispersion coefficient, and upstream inflow rates. Any attempt to determine the potential impact of restoring tidal flows to an 
acidic flood mitigation drain must consider a range of water quality conditions (i.e. high and low ionic strength).

To date, the primary method to predict the potential impacts of tidal flows on drainage systems involves shortterm floodgate openings and sandbagging of suspected overtopping hotspots. This procedure is time-consuming, crude, and may not be indicative of long-term environmental outcomes due to concerns involved with short-term floodgate openings (Johnston et al. 2002; Glamore 2003). Furthermore, restoring tidal flows for short time periods (i.e. 1-3 days) does not give a good indication of the range of water quality and tidal conditions likely to be encountered following floodgate modifications.

Due to the large number of floodgate modifications currently under way, a scientifically rigorous and tested methodology is immediately required to assist floodplain managers in safely restoring tidal flows. The method should incorporate a range of water quality and tidal conditions typical of a selected field site, and the results should be easily interpretable by both local landholders and floodplain managers. Outcomes from any proposed methodology should be incorporated into the management guidelines for the site, with particular reference to floodgate design and construction.

This paper presents a 2-stage decision support tool (DST) for restoring tidal flows using a calibrated ion-association water quality model and geographic information system (GIS) technique. Stage 1 of the DST calculates the quantity of water permitted within the drain without overtopping. Stage 2 uses results from Stage 1 to simulate the change in water quality following tidal restoration at a particular field site. As a case study, the DST is applied to an ASSaffected drainage system near Berry in south-eastern New South Wales (NSW). Stage 3 of the DST, which details the impact of saline intrusion on the subsoil matrix, is presented elsewhere (Glamore 2003).

\section{Materials and methods}

The experimental site was established on a low-lying ASS-affected floodplain near the town of Berry, NSW $\left(34^{\circ} \mathrm{S}, 150^{\circ} \mathrm{E}\right)$. The site is composed of a flood mitigation network consisting of a primary drain ( $10 \mathrm{~m}$ wide by $3 \mathrm{~m}$ deep) fed by circumneutral upland inflow and acidic groundwater drainage, and several secondary feeder drains, which drain the surrounding floodplain and discharge highly acidic surface waters $(\mathrm{pH}<3.0)$ into the primary drain (Fig. 1). An active ASS layer is found approximately $1 \mathrm{~m}$ below the soil surface across the entire study site. One-way floodgates that restrict tidal flushing were installed during the 1960 s where the drainage network discharges into Broughton Creek, a left-bank tributary of the Shoalhaven River. A small levee bank runs throughout the length of the drainage network, although the height of the levee bank varies with distance.

\section{Water quality testing}

Triplicate water quality samples were obtained by grab sampling from 3 locations within the estuary to represent high ionic $(>15 \mathrm{mS} / \mathrm{cm})$, medium ionic $(5-15 \mathrm{mS} / \mathrm{cm})$, and low ionic $(<5 \mathrm{mS} / \mathrm{cm})$ conditions. Acidic water samples were collected from the secondary side drain
(Fig. 1). Once collected, the samples were stored at $4^{\circ} \mathrm{C}$ until laboratory analysis could be undertaken.

Titration tests were conducted in the laboratory to simulate the mixing of alkaline creek water with acidic drain water. Samples were titrated at increasing concentrations of $0 \%$ to $200 \%$ at $10 \%$ increments. Each sample was then removed and tested for concentrations of total alkalinity, total dissolved $\mathrm{Fe}$, dissolved $\mathrm{Fe}^{2+}$, monomeric $\mathrm{Al}^{3+}$, total dissolved manganese, dissolved chloride, dissolved sulfate, $\mathrm{pH}$, electrical conductivity $(\mathrm{EC})$, and redox potential. Cations were tested using atomic adsorption spectrometry and anions were tested by ion chromatography (APHA 1994). Total alkalinity was measured using methods described by Neal (2001). Moreover, pH, EC, and redox potential were measured using calibrated field and laboratory probes.

\section{Ion association modelling}

PHREEQC is an open interface program developed by Parkhurst (1995) to simulate chemical reactions in natural or polluted waters based on equilibrium chemistry of aqueous solutions reacting with minerals, gases, solid solutions, exchangers, and sorption surfaces. To account for high ionic strength (sodium chloride dominated) solutions, PHREEQC incorporates the ionic-strength term within the DebyeHückel expression (Parkhurst et al. 1990). In this study, a mixing program was written and applied within the 1-dimensional open framework model to simulate chemical speciation and mixing over varying ionic conditions. The results from the program were then calibrated against the laboratory titration tests to evaluate the mixing of alkaline creek waters of varying ionic strengths with acidic drain water rich in aluminium and iron. The main inputs to the mixing program were elemental ion concentrations and EC (i.e. ionic strength).

The assumptions made for the mixing program are summarised below:

(1) Creek water entering the drain completely mixes with acidic drain water. This assumption was justified at the study site by Ikin (2001), following an in-depth study. Ikin (2001) reported that due to the relatively shallow depth of the drain $(\sim 3 \mathrm{~m})$, the high boundary friction coefficient, and the induced mixing caused by tidal ingress through modified floodgates, only minimal stratification will occur.

(2) Neutralisation agents are equally distributed throughout the drain. Although the conversion of bicarbonate ions to carbonic acid will reduce the buffering capacity with distance, the continual tidal influx replenishes bicarbonate concentrations. Further expansion of the model to incorporate 2-dimensional bicarbonate consumption is recommended if applications to significantly larger drainage systems are required.

\section{Geographic information systems}

To delineate drainage regimes, detailed airborne laser scanning (ALS) was undertaken across the study site by the Shoalhaven City Council. The ALS data were calibrated against known benchmarks and combined with cross-sectional surveying of the drains at $50-\mathrm{m}$ intervals. These datasets were incorporated within ArcGIS (version 8.1) to form a digital terrain model (DTM) of the study site (Fig. 2). Based on the high resolution of the ALS and subsequent ground-truthing, the DTM accuracy was within $\pm 0.06 \mathrm{~m}$.

Submersible water level sensors were installed within the flood mitigation drain and in the Broughton Creek for a period of 1 year prior to floodgate modifications, in order to calculate tidal dampening and typical tidal fluctuation levels. Using these measurements, it was calculated that $90 \%$ of tidal levels within Broughton Creek were below $0.71 \mathrm{~m}$ Australian Height Datum (AHD) (Glamore 2003). Excluding major rainfall events, $99 \%$ of all tidal levels were calculated at $0.91 \mathrm{~m}$ AHD. Mean drain water levels were calculated at $0.28 \mathrm{~m}$ AHD. To determine appropriate freeboard levels permitted within the drain, water 

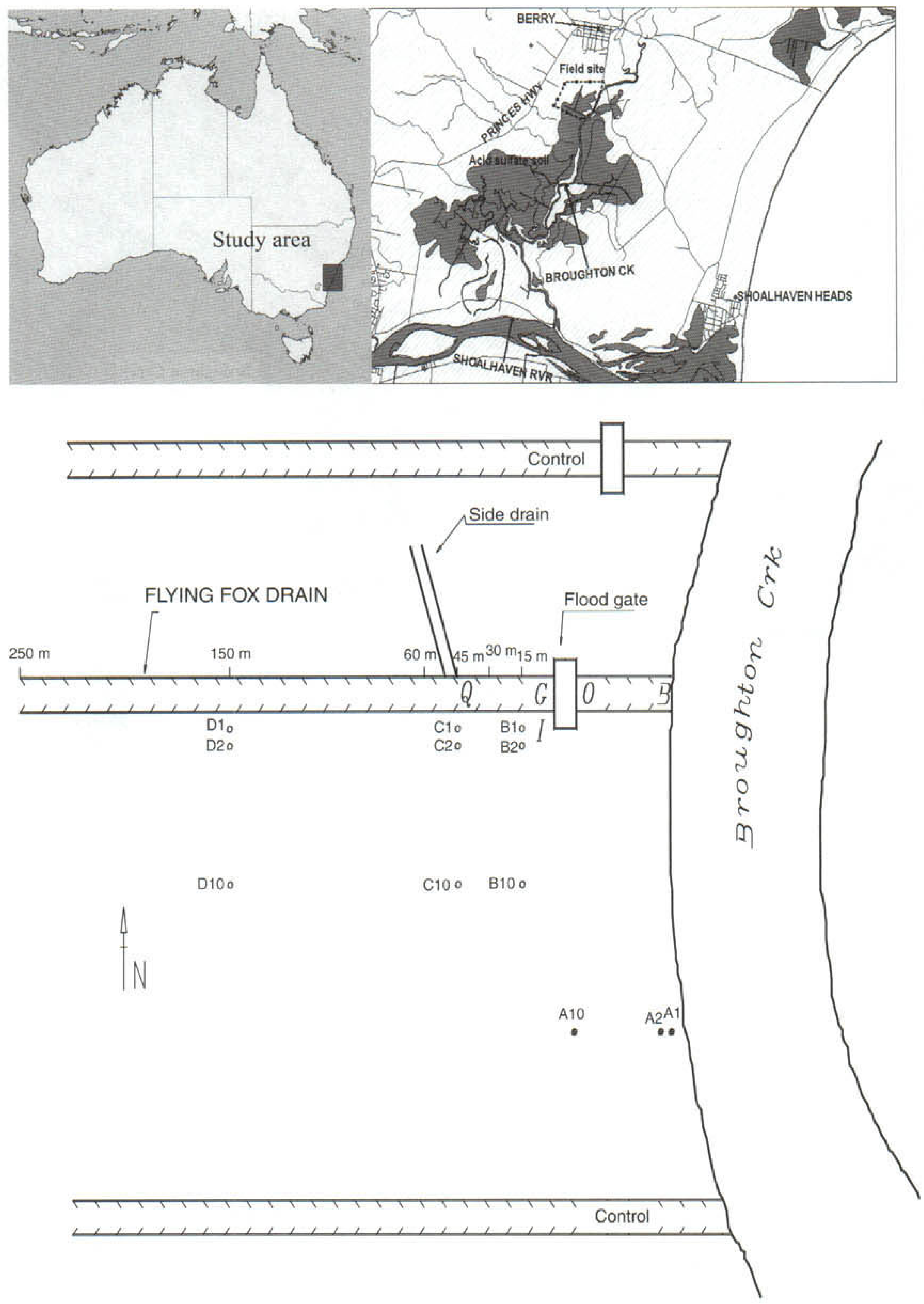

Fig. 1. Study site location with surface water (Q, G, O, B) and groundwater (A1-D10) sampling sites. 


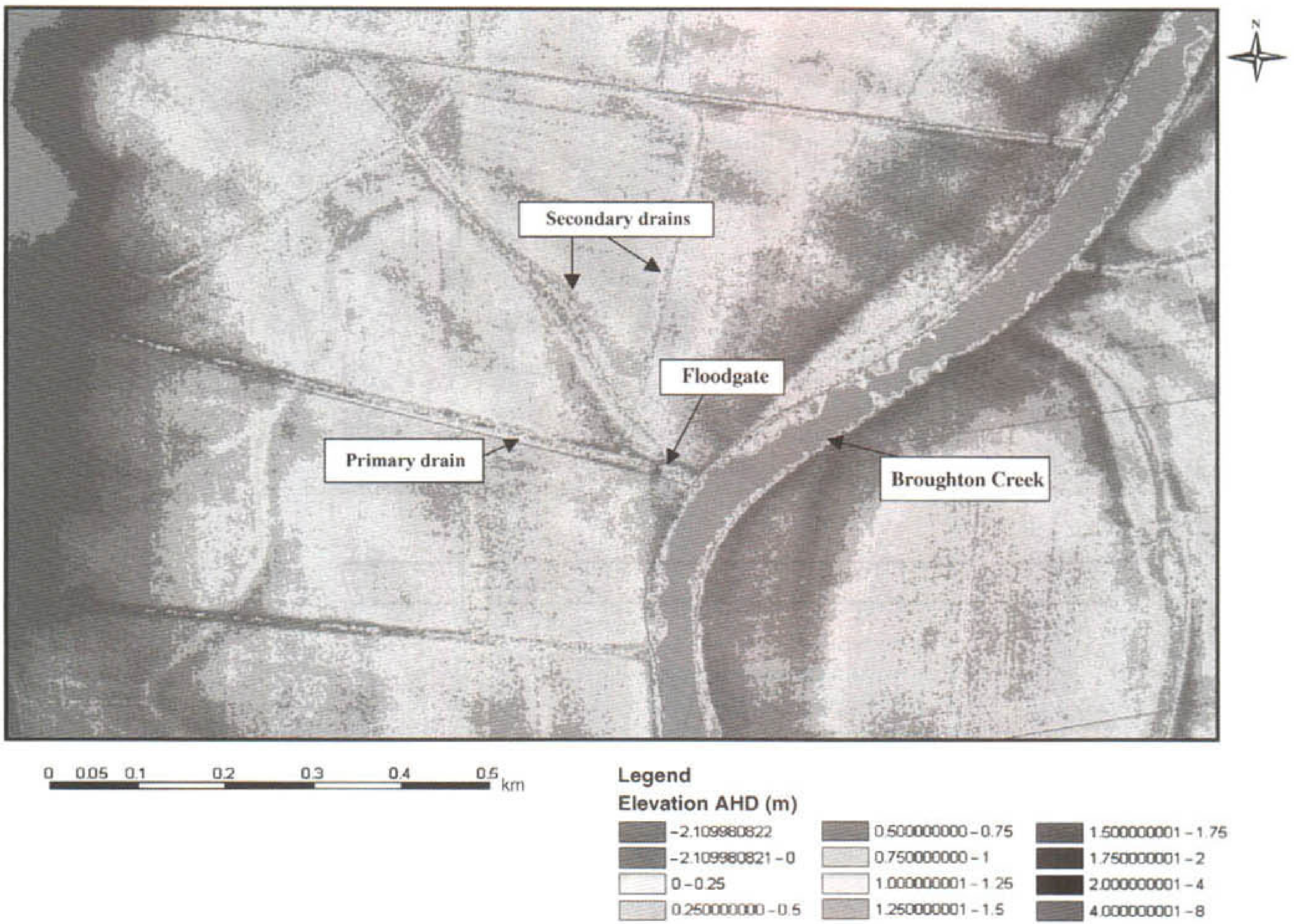

Fig. 2. Digital terrain map of study site.

elevations were set within the DTM using the raster calculator tool within the spatial analyst extension. Specifically, drain water elevations were set at $0.91 \mathrm{~m} \mathrm{AHD}$ and $0.71 \mathrm{~m} \mathrm{AHD}$, representing the highest drain water elevation anticipated and the average high tide level, respectively.

\section{Results}

\section{Stage 1: GIS flood estimation technique}

Spatial simulations using the flood estimation technique showed that drain overtopping was not a concern within the primary drainage network when water elevations were set to $0.71 \mathrm{~m}$ AHD. As depicted in Fig. 3, tidal intrusion extended $234 \mathrm{~m}$ upstream of the floodgate within the primary study drain and throughout the length of the secondary side drain. These results suggest that for $95 \%$ of all tidal conditions, full tidal flushing could be permitted within both drainage networks. By contrast, when the drain water level was set at $0.91 \mathrm{~m}$ AHD, significant overtopping would be expected to occur in the secondary side drains (Fig. 4). In this scenario, drain overtopping was evident along relic drainage channels, which were filled during the construction of the present drainage network. Conversely, close-up examination of the primary drain with water levels set at $0.91 \mathrm{~m}$ AHD (Fig. 5) showed that the levee bank was sufficient to restrict overtopping.

The GIS flood estimate technique detailed above showed that full tidal flushing can be permitted within the primary drain but tidal levels $>0.71 \mathrm{~m}$ AHD would need to be restricted within the secondary drains. This management strategy is feasible because a series of small floodgates are located at the discharge points of each secondary drain. Furthermore, these results indicate that a $58 \%$ increase in drain water levels $(0.71 \mathrm{~m}$ AHD $v$. long-term drain water levels of $0.28 \mathrm{~m} \mathrm{AHD)}$ can be permitted within the primary drain without overtopping.

\section{Stage 2: ion association mixing model}

To determine the impact of tidal restoration on drain water quality, a mixing program was written, run and calibrated within the PHREEQC program framework. The calibration results (Figs 6 and 7) indicated that the model strongly correlates with laboratory measurements for both low and high ionic waters. Moreover, the calibrated results depicted an improvement in water quality with mixing, with the slope 


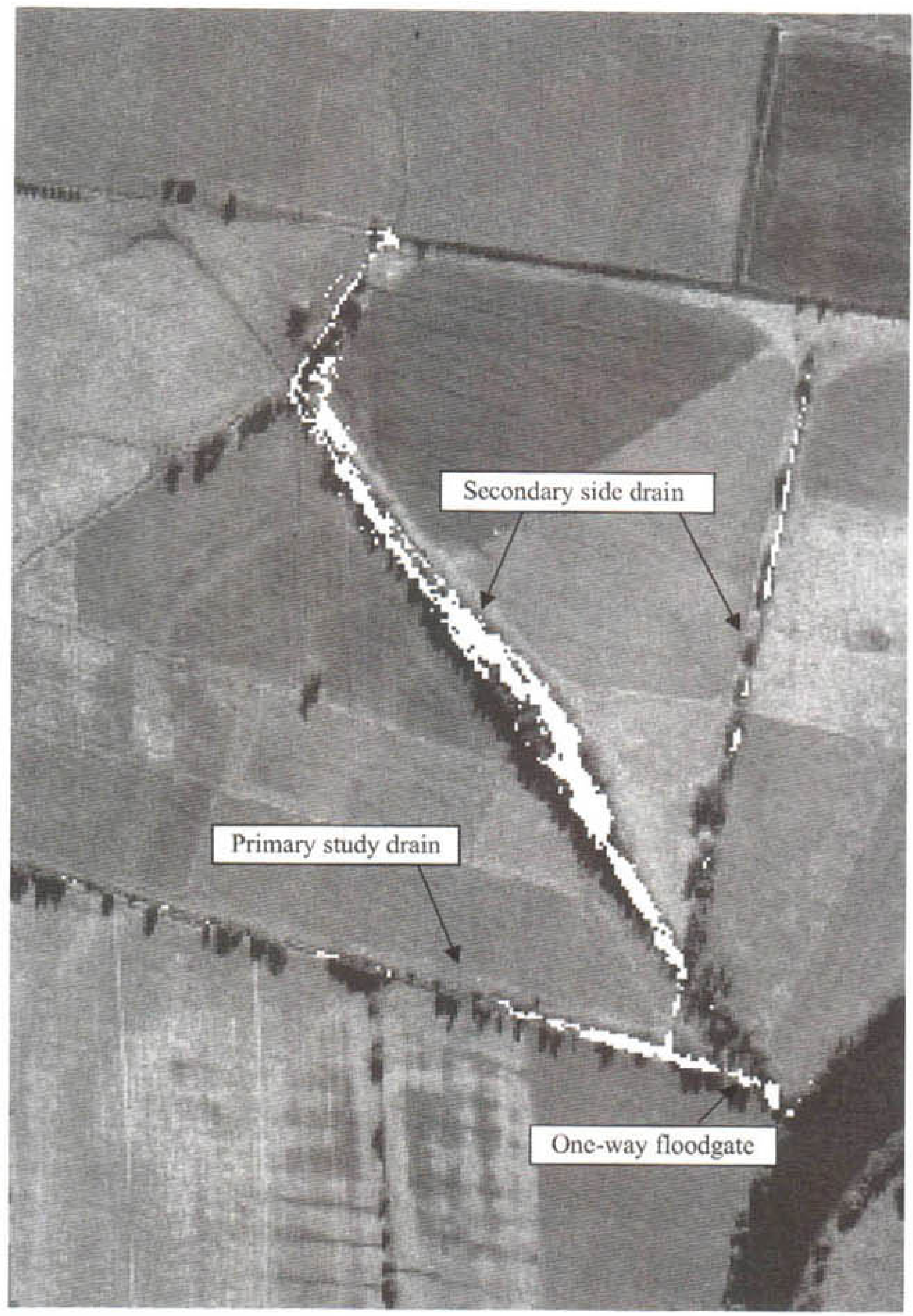

Fig. 3. Drain water elevations at $0.71 \mathrm{~m}$ AHD within the study drain and secondary side drains. The predicted water level is indicated by the white shading within the drain.

of the water quality improvement dependent on the ionic strength of the intruding (alkaline) water.

As expected, the calibrated ion association model showed that waters with higher ionic strength (Fig. 6) decreased the total soluble acidity with less proportional mixing than weaker ionic strength samples (Fig. 7). This was due to the decreased solubility rates of highly ionic solutions and the increased concentration of buffering agents in the highly ionic samples. The reaction path kinetics (Figs 6 and 7 ) for 4 typical ASS indicators ( $\left.\mathrm{Fe}, \mathrm{Al}, \mathrm{pH}, \mathrm{SO}_{4}\right)$ are detailed below.

In natural waters, aluminium solubility is pH-dependent and typically insoluble at pH 5-9. Monomeric inorganic aluminium solubility is complicated due to the formation of partially dissociated $\mathrm{Al}(\mathrm{OH})_{3}$ species and complexing between aluminium and organic matter. Aluminium commonly complexes with dissolved sulfate as $\mathrm{AlSO}_{4}$ or as $\mathrm{Al}\left(\mathrm{SO}_{4}\right)_{2}$ in acidic conditions if sulfate is abundant, but as $\mathrm{pH}$ increases, $\mathrm{Al}^{3+}$ undergoes hydrolysis resulting in a series of $\mathrm{OH}^{-}$complexes (such as $\mathrm{Al}(\mathrm{OH})^{2+}$ and $\mathrm{Al}(\mathrm{OH})_{2}^{+}$) and reduced solubility (Glamore 2003). The formation of aluminium hydroxide precipitates is depicted in Eqns 1 and 2:

$$
\begin{aligned}
\mathrm{Al}_{(\text {aq) }}^{3+}+3 \mathrm{OH}_{(\mathrm{aq})}^{-} & \leftrightarrow \mathrm{Al}(\mathrm{OH})_{3(\mathrm{~s})} \\
\mathrm{Al}(\mathrm{OH})_{3(\mathrm{~s})}+\mathrm{OH}_{(\mathrm{aq})}^{-} & \leftrightarrow \mathrm{Al}(\mathrm{OH})_{4}^{-}
\end{aligned}
$$




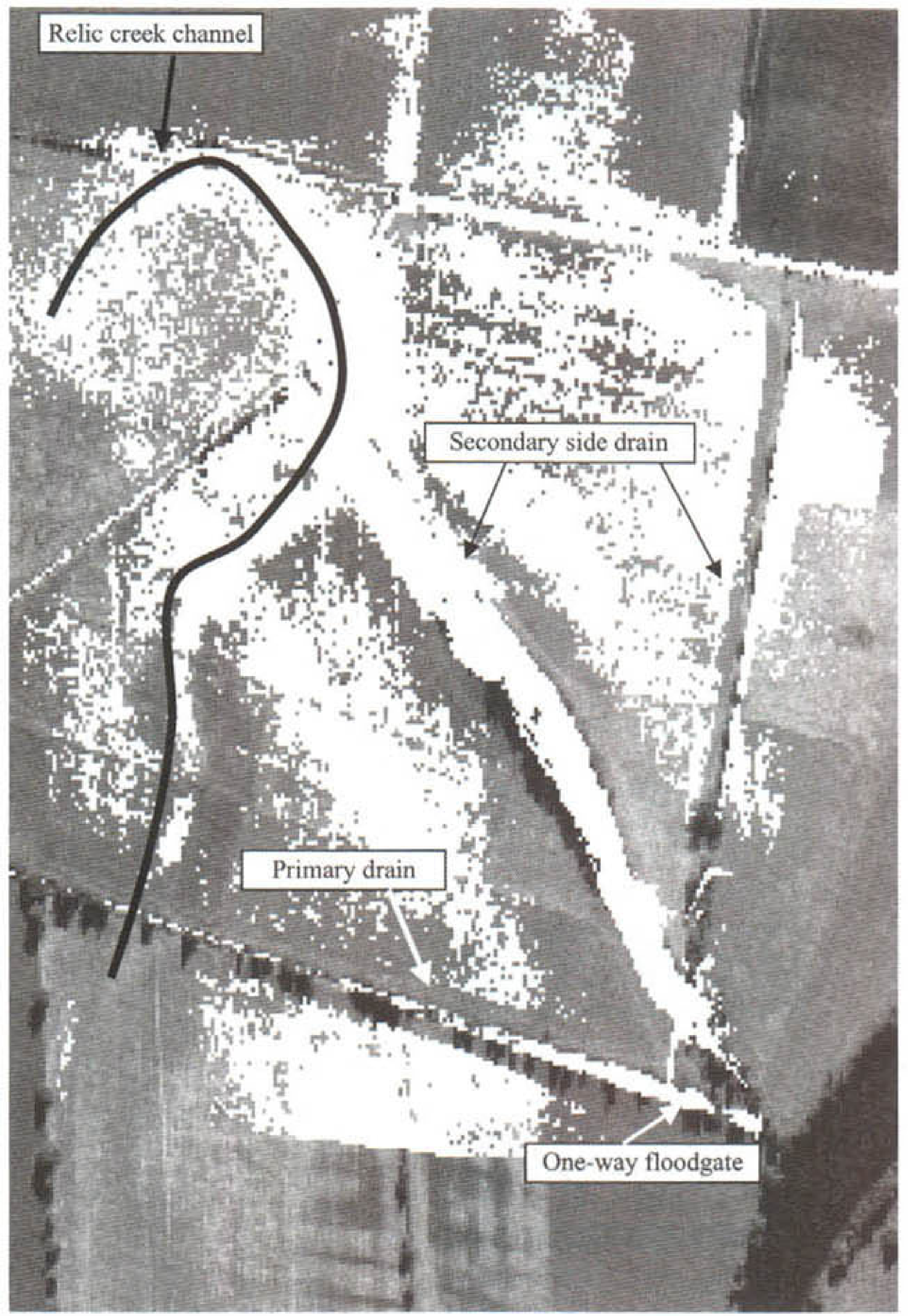

Fig. 4. Drain water elevation at $0.91 \mathrm{~m}$ AHD within the study drain and secondary side drain.

The mixing model and the laboratory results both indicate that increased drain water $\mathrm{pH}$ due to tidal buffering via modified floodgates will decrease the soluble aluminium concentrations. As the toxicity of soluble $\mathrm{Al}^{3+}$ is significantly reduced in drainage waters with $\mathrm{pH}>6.5$, increasing drain water $\mathrm{pH}$ via tidal buffering will also reduce acidic ion solubility.

Total dissolved iron concentrations are dependent on $\mathrm{pH}$ and redox potential measurements. Generally, iron is only soluble under low redox or in acidic conditions as $\mathrm{Fe}(\mathrm{II})$. At the study site, drain water quality prior to floodgate modifications was acidic with low dissolved oxygen levels.
The mixing model and laboratory results (Figs 6 and 7) suggest that modifying the floodgate to permit tidal flushing will increase Eh and remove soluble Fe(II) from the drainage waters. Conversely, the oxidation of $\mathrm{Fe}(\mathrm{II})$ and the formation of insoluble iron hydroxides release $\mathrm{H}^{+}$ions into solution, which explains the limited increase in $\mathrm{pH}$ during initial mixing.

By contrast with aluminium and iron, sulfate solubility is not generally pH-dependent. In Figs 6 and 7, the majority of sulfate ions were removed from solution within $20 \%$ mixing. This was attributed to the affinity of sulfates to bind with calcium to form gypsum $\left(\mathrm{CaSO}_{4} \cdot 2 \mathrm{H}_{2} \mathrm{O}\right)$. 


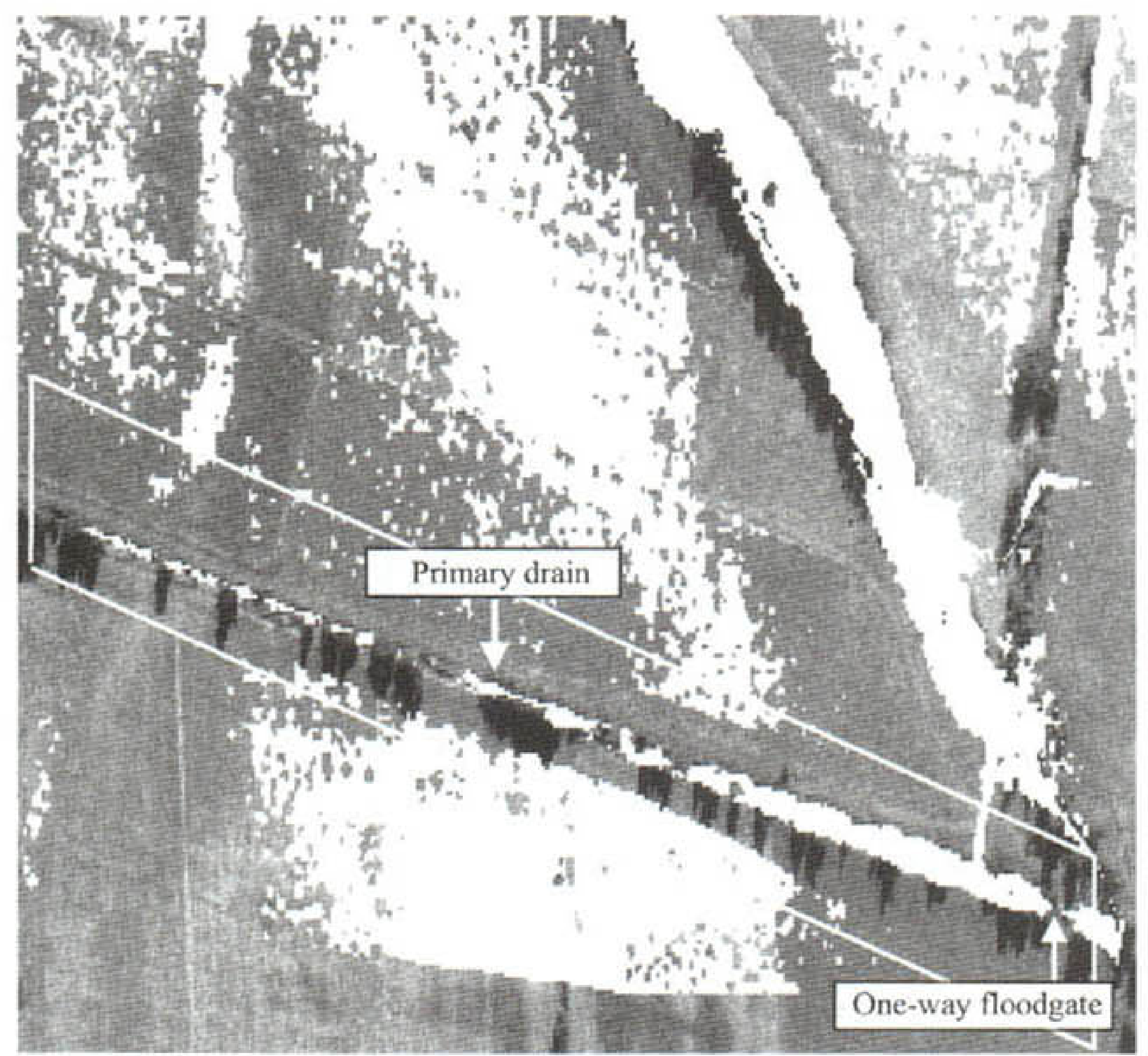

Fig. 5. Levee bank region in primary drainage network with water elevation set at $0.91 \mathrm{~m}$ $\Lambda \mathrm{HD}$. Note the lack of white colouring linking the drain with the surrounding floodplain.

Gypsum $\left(\mathrm{CaSO}_{4}\right)$ is generally insoluble, because when sulfate complexes with calcium, the salts charge over the ionic radius decreases. Under reducing conditions with high iron content, sulfates can also precipitate as iron monosulfides or MBOs (monosulfide black oozes). On the other hand, elevated dissolved sulfate concentrations can be derived from tidal waters (seawater concentrations $2700 \mathrm{mg} / \mathrm{L}$ ), which mask acidic contributions.

The above results indicate that alkaline buffering will generally improve water quality by increasing $\mathrm{pH}$ and decreasing metal solubility. Based on these findings and using the calibrated water quality model, a series of simulations were undertaken to determine resultant drain water quality under fluctuating tidal/climatic regimes (i.e. high ionic $v$. low ionic conditions) at the study site. These predictions were undertaken to determine whether floodgate modifications at the study site would significantly improve drain water quality using the calculated volume of tidal water required within the drain (determined during stage 1). The results from these tests for both wet (low ionic) and dry (high ionic) climatic periods are shown in Fig. 8.

The water quality simulations depicted in Fig. 8 were developed using pre-modification drain and creek water data during wet and dry periods. The model inputs were derived from long-term water quality sampling data divided into high ionic (low upland flow, strong buffering capacity) $v$. low ionic (strong upland flow, weak buffering capacity) periods based on EC. All water quality samples $<5.0 \mathrm{mS} / \mathrm{cm}$ were deemed low ionic, while all samples $>15.0 \mathrm{mS} / \mathrm{cm}$ were deemed highly ionic. Acid water inputs were obtained by averaging all relevant drain water quality records before floodgate modification, and the resultant concentrations were then used as inputs in the source code.

Simulations of water quality at the study site after floodgate modifications (Fig. 8) indicate that drain water quality will significantly improve during both high and low ionic creek conditions. In general, with increased mixing, acidic cation solubility decreased in a non-linear fashion, which illustrates that buffering as well as dilution is important for removal of metal contaminants. The small disparity in water quality results between ionic conditions was attributed to the increased salt quantities in solution, which have a tendency to suppress metal-ion activity and/or increase solution pairing/complexation (Fig. 8), thereby inhibiting mineral precipitation.

As shown in Fig. 8, pH values rapidly increased with creek water mixing and varied between ionic conditions. Under high ionic conditions, $\mathrm{pH}$ increased from 4.49 to 6.02 in $<50 \%$ mixing, which was attributed to the elevated bicarbonate concentrations of high ionic waters $(87.86 \mathrm{mg} / \mathrm{L}$ in high ionic $v .17 .98 \mathrm{mg} / \mathrm{L}$ in low ionic waters). In terms of management practices, it is important to note that the abrupt 

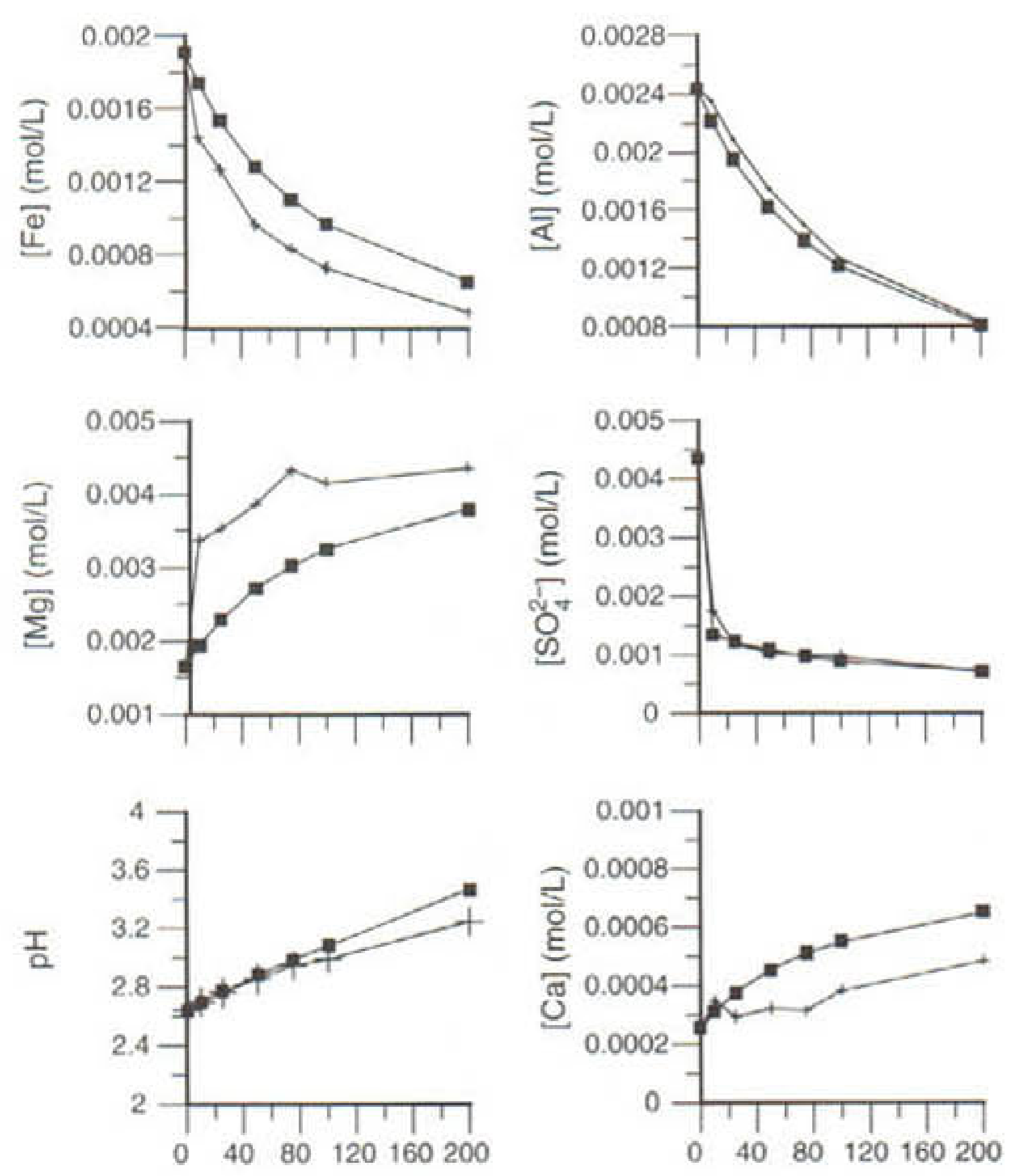

Per cent mixing

Fig. 6. Laboratory results $(+)$ compared with PHREEQC simulations $(\square)$ for low ionic strength samples taken from Broughton Creek.

increase in $\mathrm{pH}$ levels was achieved with only a relatively small quantity $(\sim 50 \%)$ of tidal water to significantly improve drain water conditions. Indeed, a $58 \%$ mixing proportion (the equivalent to full tidal restoration within the primary drain) equates to a predicted drain water $\mathrm{pH}$ of 6.02 .

\section{Discussion}

The 2-stage DST presented above provides indicative information on flood estimation and water quality with regard to combating ASS leachate in low-lying flood mitigation drains. Application of the flood estimation technique showed that full tidal restoration could only be permitted within the primary drainage network. While $95 \%$ of all tides can safely be restored to the secondary drainage network, large king tides could cause flooding of the backswamp region along relict drainage channels. Importantly, this technique is a significant improvement on current 'sandbagging' methods, which are time-consuming and imprecise, and do not provide a good indication of drain water levels over time. Moreover, application of this technique at the study site provides tangible evidence of the altered conditions prior to costly civil works, which may have major implications on floodgate design and construction (i.e. automated $v$. static designs).

Results from the water quality simulations also have important implications for ASS management. Specifically,
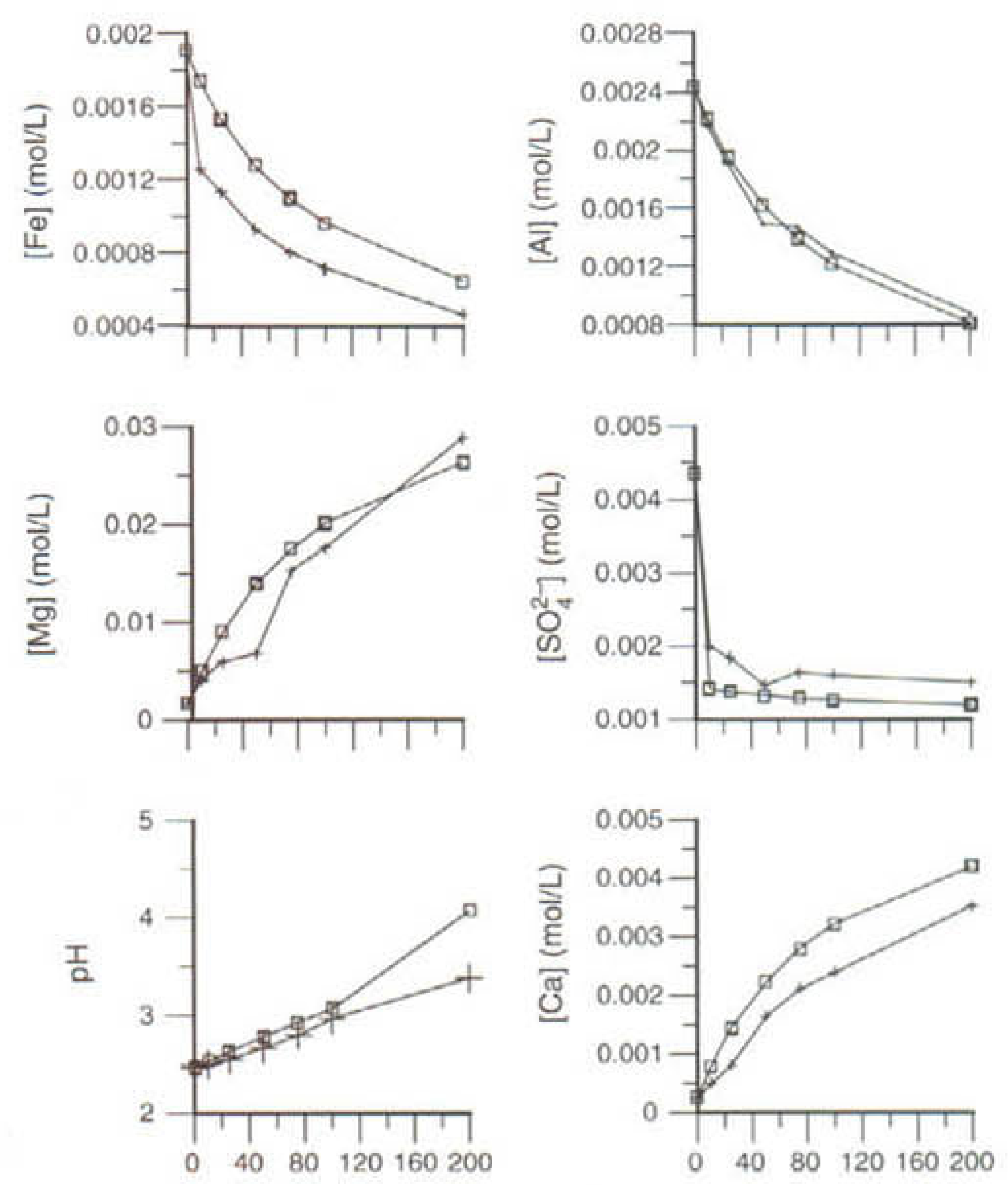

Per cent mixing

Fig. 7. Laboratory results (+) compared with PHREEQC simulations $(\square)$ for high ionic strength samples taken from Broughton Creek.

improvements in water quality were shown regardless of ionic capacity; however, better water quality results were achieved with water that was highly ionic. This has repercussions for floodgate management, because it indicates that increased water quality is associated with increased salinity levels, and hence, the increase in surface water salinity may have the potential to influence groundwater quality. The fluctuations in surface water quality with ionic capacity also show that the flushing dynamics of the estuary should be taken into account when determining acceptable water quality criteria for any tidal restoration management strategy.

Simulations using the calibrated water quality model highlight important reaction kinetic pathways. Firstly, as shown in Fig. 8, it is important to note that a significant improvement in water quality can be achieved with slightly brackish water. This is important for management, because it suggests that regions with low concentrations of buffering agents (i.e. backswamps with minor tidal variations) can still have beneficial influences from floodgate manipulation. Secondly, the model illustrates the reaction path kinetics of major ions during tidal buffering and can be employed to set management criteria based on desired concentrations. Finally, during the modelling process, $\mathrm{pH}$ levels fluctuated most in response to variations in aluminium concentrations. This demonstrates that the removal of aluminium via 

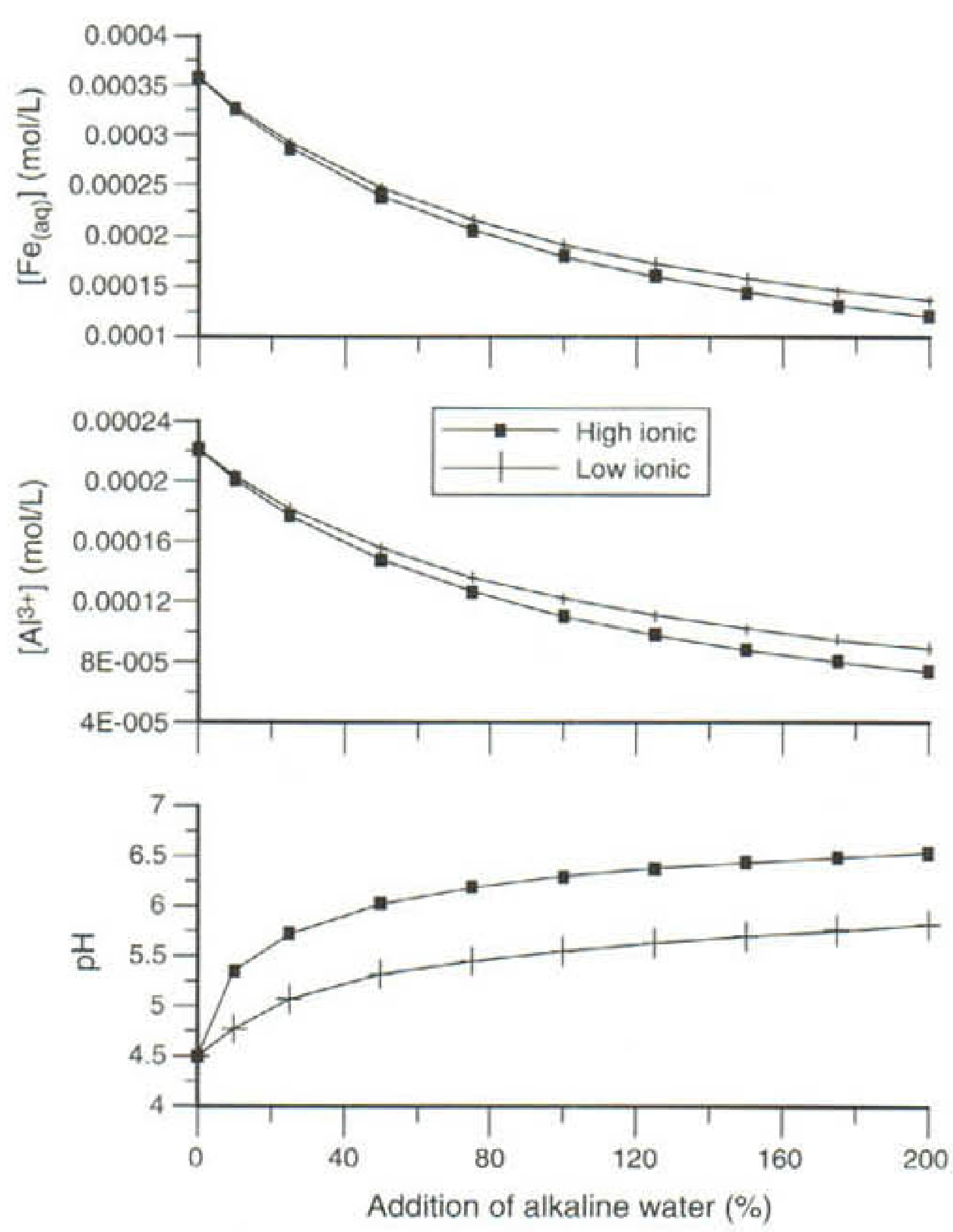

Fig. 8. Simulations of drain water quality following mixing with alkaline creek water.

mineral precipitates or through mineral surface sorption will significantly decrease drain water total acidity, and that any future research to combat ASS leachate may be best focused on reducing aluminium solubility.

Based on the results of the DST, which suggested significant benefits to drain water quality $(\mathrm{pH}$ levels $>6.0$, decreased soluble $\mathrm{Fe}^{2+}, \mathrm{SO}_{4}$, and $\mathrm{Al}^{3+}$ ) as well as minimal flooding risks, floodgate modifications were undertaken at the study site. Full tidal flows were only restored to the primary drainage network to avoid overtopping of the risk-prone regions in the secondary drainage system. Improvements in water quality following floodgate modifications in comparison to the DST predictions are given in Table 1. The field results show that the water quality model accurately predicted the long-term drain water quality changes, with most indicators within $10 \%$ of the predicted values. One notable exception was soluble sulfate concentrations, which increased after tidal restorations due to high concentrations of sulfate in seawater $(2700 \mathrm{mg} / \mathrm{L})$. Overall, the slightly higher field concentrations were associated with drier than normal conditions at the study site, which increased the ionic capacity and, hence, the buffering capacity of the tidal waters.

As well as accurately predicting drain water quality, the 2-stage DST effectively simulated the issues related to
Table I. Drain surface water quality before and after floodgate modifications

\begin{tabular}{lcccc}
\hline & $\mathrm{pH}$ & $\begin{array}{c}\mathrm{Al}^{3+} \\
(\mathrm{mg} / \mathrm{L})\end{array}$ & $\begin{array}{c}\mathrm{Fe}(\mathrm{total}) \\
(\mathrm{mg} / \mathrm{L})\end{array}$ & $\begin{array}{c}\mathrm{SO}_{4} \\
(\mathrm{mg} / \mathrm{L})\end{array}$ \\
\hline $\begin{array}{l}\text { Mean field measurement: } \\
\text { Pre-modification }\end{array}$ & 4.32 & 11.33 & 23.07 & 985.6 \\
$\quad$ Post-modification & 6.04 & 4.38 & 10.33 & 360.0 \\
$\begin{array}{l}\text { Predicted concentration } \\
\text { post modification }\end{array}$ & 6.02 & 4.04 & 12.40 & 144.6 \\
\hline
\end{tabular}

drain overtopping. Throughout the 2-year period following floodgate modifications, sufficient freeboard was available within the primary drainage system to permit full tidal fluctuations. Automated tidal gates systems are currently being installed at the study site to permit restricted tidal flushing within the secondary drainage network.

\section{Conclusions}

The benefits of modifying 1-way floodgates to restore tidal flushing and combat ASS leachate are well reported throughout Australia. At present, crude methods are employed to determine the risks associated with modifying the drainage regime and in assessing any potential benefit in drain water quality. Within the scope of this paper, a 2-stage flood estimation-water quality DST was presented to provide a reliable, cost-effective, and accurate method of determining the impact of restoring tidal flows to a low-lying ASS-affected flood mitigation drain. The calibrated model provides a visual and analytical tool to estimate flood levels and water quality at potential floodgate modification sites. The DST was shown to effectively simulate conditions at a study site in south-eastern NSW.

The first stage of the DST (i.e. GIS flood estimation) showed that full tidal exchange could be permitted within the primary drainage network without overtopping the levee banks. Simulations within the secondary drainage network showed that while $95 \%$ of all tidal fluctuations could be allowed, tidal heights of $0.91 \mathrm{~m} \mathrm{AHD}(99 \%$ of all tidal fluctuations) caused overtopping along relic drainage channels. Based on these results, it was determined that a $58 \%$ increase in drain water could be expected within the primary drain, but that floodgate modifications could not be permitted within the secondary drains.

Within the second stage of the DST, a water quality program was written and calibrated within the open interface PHREEQC program to forecast the potential change in water quality due to tidal mixing. Results from the model show good agreement with laboratory titration tests and indicate that any change in water quality is directly related to the ionic strength of the intruding water. The results also highlighted the reaction path kinetics of several acidic species during the tidal buffering process. In combination, the first-stage flood estimation results calculated the maximum amount of water 
permitted within the drainage system. The second-stage water quality results, which determined the change in drain water quality from mixing acidic drain water with alkaline creek water, indicated that full tidal restoration could be provided to the primary drainage system to improve water quality without overtopping the levee banks.

Modifications of a floodgate to permit tidal flushing showed that the site conditions were in line with the predictions of the DST. Long-term water quality indicators were within $10 \%$ of simulated results except for sulfate concentrations, which were above predicted levels due to the high concentration of sulfate in seawater. Similarly, drain water overtopping has not occurred within the primary drain due to high tidal levels. The model presented within this paper can be applied to other similar sites in Australia to predict the water quality and flood estimation within low-lying flood mitigation drains.

\section{Acknowledgments}

We thank the Shoalhaven City Council, Marcus Morgan, Annie Cannon, and local landholders for their support and technical assistance. Funding from the University of Wollongong and the Shoalhaven City Council is gratefully acknowledged.

\section{References}

ANZECC (2000) 'Australian water quality guidelines for fresh and marine waters.' (Australian and New Zealand Environment Conservation Council: Canberra)

APHA (1994) 'Standard methods for the examination of water and wastewater.' 18th edn (American Public Health Association: Washington, DC)
Glamore W (2003) Evaluation and analysis of acid sulfate soil impacts via tidal restoration. PhD thesis, University of Wollongong, Australia.

Glamore W, Indraratna B (2001) The effects of floodgate modifications in acid sulfate soil terrains. In 'Proceedings of 15 th Australasian Coastal and Ocean Engineering Conference'. Gold Coast, Qld. (Eds B Mcgrath, M Gourlay, P Nielsen) pp. 265-270. (The Institution of Engineers: Sydncy)

Glamore W, Indraratna B (2002) Management of acid sulfate soil drainage via floodgate manipulation. In 'Proceedings of 5th International Conference on Acid Sulphate Soils'. Tweed Heads, NSW. pp. 75-77. (Department of Agriculture: Tweed Heads, NSW)

Ikin D (2001) Stratification of acid sulphate soil affected waters. BE Honours thesis, The University of Wollongong, Australia.

Indraratna B, Glamore W, Tularam GA (2002) The effects of tidal buffering on low-lying ASS environments. International Journal of Geotechnical and Geological Engineering 20, 181-199. doi: 10.1023/A:1016075026487

Johnston SG, Slavich P, Hirst P (2002) Floodgate and drainage system management: opportunities and limitations. An acid export perspective. In 'Proceedings of 5th International Conference on Acid Sulphate Soils'. Tweed Heads, NSW. (Department of Agriculture: Tweed Heads, NSW)

Neal C (2001) Alkalinity measurements within natural waters: towards a standardized approach. The Science of the Total Environment 265, 99-113. doi: 10.1016/S0048-9697(00)00652-5

Parkhurst D (1995) PHREEQC - A computer program for speciation, reaction-path, advective transport, and inverse geochemical calculations. Water Resources Investigations Report No. 95-4227. US Geological Survey, Lakewood, CO, USA.

Parkhurst DL, Thorstenson DC, Plummer LN (1990) PHREEQEA computer program for geochemical calculations. US Geological Survey of Water Research 80-96.

Manuscript received 3 December 2003, accepted 16 March 2004 